\title{
Urinary Bladder Hemorrhage
}

National Cancer Institute

\section{Source}

National Cancer Institute. Urinary Bladder Hemorrhage. NCI Thesaurus. Code C78674.

Bleeding orig inating from the urinary bladder wall. 